Full Length Article

\title{
Exploring the stigma related experiences of family members of persons with mental illness in a selected community in the iLembe district, KwaZulu-Natal
}

\author{
Celenkosini Thembelenkosini Nxumalo ${ }^{a, *}$, Gugu Gladness Mchunu ${ }^{b}$ \\ ${ }^{\text {a }}$ KZN Department of Health - Ndwedwe Community Health Centre, Private Bag X 528, Ndwedwe 4342, South \\ Africa \\ b School of Nursing and Public Health, University KwaZulu-Natal Howard College, 5th Floor George Campbell \\ Building, South Africa
}

\section{A R T I C L E I N F O}

Article history:

Received 24 March 2016

Accepted 21 February 2017

Keywords:

Stigma

Experiences

Family members

Persons with mental illness

Community

\begin{abstract}
A B S T R A C T
Background: Stigma in mental illness is a serious social problem which has a multitude of consequences on the individual concerned, as well as his or her family. Research has shown that families of persons living with mental illnesses are often subjected to stigma by virtue of their association with such a person. The stigma of families is seen in the form of assignment of blame, social isolation and rejection. This stigma subsequently perpetuates a cycle of disability on the part of the patient and family.

Purpose: To explore the stigma related experiences of family members of persons with mental illness in a selected community in the iLembe district of KwaZulu-Natal (KZN), in order to develop recommendations to help families cope with such stigma.

Methods: This was a descriptive qualitative study; data was collected from a purposive sample of six family members, which resulted in data saturation. Semi-structured interview questions were used during data collection and content analysis using Creswell's (2009) method was done to analyse the data; resulting in the formation of themes and subthemes which were supported by the participants' responses and existing literature.

Results: Participants reported experiencing stigma from the community in the form of isolation, blame and exploitation, community neglect, as well as labelling and stereotyping. The majority of the participants reported using emotion-focused coping mechanisms to deal with the stigma they faced. Participants suggested that education of communities regarding the myths and facts about mental illness may help to curb the stigma faced by the family members of persons with mental illness.

Conclusion: Based on the results of this study, it was recommended that a combination of coping strategies, together with the integration of public and private sector support, be used to holistically deal with family related stigma. It was found that ground level
\end{abstract}

\footnotetext{
* Corresponding author.

E-mail address: Thembz92@gmail.com (C.T. Nxumalo).

Peer review under responsibility of Johannesburg University.

http://dx.doi.org/10.1016/j.hsag.2017.02.002

1025-9848/@ 2017 The Authors. Publishing services by Elsevier B.V. on behalf of Johannesburg University. This is an open access article under the CC BY-NC-ND license (http://creativecommons.org/licenses/by-nc-nd/4.0/).
} 
education and support to families is the key to curbing family related stigma of mental illness, local NGO's and the clinics would be instrumental in this area.

(c) 2017 The Authors. Publishing services by Elsevier B.V. on behalf of Johannesburg University. This is an open access article under the CC BY-NC-ND license (http:// creativecommons.org/licenses/by-nc-nd/4.0/).

\section{Introduction and background}

Stigma in mental illness is a serious social problem which is exhibited by society's general fear, lack of respect and refusal to accept a person living with a mental disorder (Bonfine, 2015; Ustun, 1999). It is associated with a multitude of direct and indirect consequences which are long term and have effects on the individual concerned, his or her family, the community and possibly the society at large (Rithsher, Otilingam, \& Grajales, 2003). According to the International council of Nurses (ICN, 2015) stigma related to mental illness has negative implications on the health and well-being of the patient, their family and even health care workers.

Stuart (2004) states that the stigma of mental illness perpetuates a cycle of disability on the part of the patient as well as the family and is thus difficult to reverse because change is contingent upon behavioural modification. Stigma impedes the person with mental illness from recovering by eroding their self-worth and esteem, resulting in a failure to comply with treatment or delayed treatment seeking which aggravates the well-being of the person affected and as a result affects the family (Ritsher \& Phelan, 2004). It is significant to note that the diagnosis of mental illness does not only affect the individual but also the family of the affected person (Dalky, 2012). Sanden, Bos, Stutterheim, Pryor and Kok (2014) state that the individuals with mental illness are not the only ones that are affected by stigma, but the families of such individuals are also subjected to stigma by virtues of their association with them.

Typically, the stigma of families contains stereotypes of blame, shame, social rejection and a combination of other related attitudes towards the family (Larson \& Corrigan, 2008). Consequently, this perpetuates a lack of motivation in helping the person with mental illness during the recovery process, thus the results of this are prolonged sickness which has financial and emotional implications on the family affected (Wong et al., 2009). In addition, the affected family may even cease to play a role in the community when they are discriminated against as a result of being associated with a person with mental illness (Byrne, 2000).

\section{Problem statement}

Studies conducted on the stigma of mental illness have revealed that such stigma not only affects the individuals with mental illness, but also the family members of these individuals. Literature has documented extensively on the consequences of stigma and therefore interventions to curb the stigma of mental illness; whether faced by the individual with mental illness or the family, are necessary. Although much research has been done on stigma in mental illness, the majority of studies that have been conducted have mainly focused on the individual with mental illness thus, neglecting the family who is also affected by this stigma.

Although knowledge of the existence of family related stigma of mental illness is known, only a few studies have explored this stigma, it can therefore be stated that little is known regarding the stigma faced by families of persons living with mental illnesses, particularly those living within the rural areas of South Africa. It is therefore necessary to conduct research to explore the stigma related experiences of family members of persons with mental illness so as to create an awareness of the patterns of family related stigma of mental illness within the rural context of South Africa. Furthermore, knowledge of such patterns of stigma maybe valuable in contributing to the development of recommendations to assist families to cope with the stigma.

\section{Significance of the study}

This study is valuable in contributing to the awareness and prevention of stigmatisation of people with mental illness and their families in rural South Africa.

\section{Aim}

This study aims to explore and describe the stigma related experiences of family members of persons with mental illnesses, in a selected community in the iLembe district of KwaZulu-Natal (KZN), in order to develop recommendations on how families can be assisted to cope with such stigma.

\section{Research questions}

- What are the stigma related experiences of the family members of people who have mental illnesses in a selected community in the iLembe district?

- How do family members deal with such stigma related experiences?

- What recommendations can be made to curb the stigmatisation of family members of persons with mental illness in the community?

\section{Research objectives}

- To describe the stigma related experiences of the family members living with a person who has a mental illness, in a selected community in the iLembe district.

- To explore how family members have dealt with such stigma related experiences. 


\section{Operational definitions}

Experiences: According to Waite and Hawker (2009), experiences are an account of events or situations which leave an impression on someone. In this study, experiences are defined as a family member's accounts of stigma related feelings, situations or instances which have had an impact on them emotionally, socially or interpersonally.

Mental illness: Refers to a collection of conditions in which the emotional, social, cognitive and interpersonal well-being of a person is interrupted. Often mental illness is clinically diagnosed using a Diagnostic and Statistical Manual (DSM) of mental disorders (Caplan, 1993; Shives, 1994). In this study, mental illness refers to any mental disorder such as schizophrenia, bipolar disorder or any other mental health related disorder, which has been diagnosed by mental health professionals using the DSM 5 TM classification.

Stigma: It is a negative view, attitude, belief or action placed on an individual, group or minority, which has negative effects on whoever it may be placed (Hayward \& Bright, 1997). In this study, stigma is referred to as any attitude, behaviour or label placed on a mentally ill person and his or her family or family members, that is negative or demeaning to them.

Family members: For this study, it refers to those individuals who are biologically or socially related (sibling, spouse, mother or father) to the person with a mental illness or whom the patient regards as family, and who have been living with the patient for a period of six months or more.

People or persons with mental illness: In this study, it refers to any individual(s) who has been clinically diagnosed (irrespective of the type of diagnosis) as mentally ill by a medical practitioner and has had such a diagnosis for a period of one year or more.

Community: According to the WHO (2004), a community is a group of people living within a clearly delineated geographic area, who share common values and norms. They are arranged according to a particular social structure, they know and interact with each other and exhibit some awareness of their identity as a social group. In this study, the community refers to the members that form part of or make up the headcount of the facility at which the data is to be collected. It includes both the mental health care users and the family members that accompany them when they attend the mental health care clinic.

\section{Research method and design}

\subsection{Design}

For the purpose of this research a descriptive qualitative study was used to explore the stigma related experiences of the family members of persons with mental illness. The qualitative approach to research is useful in instances where the researcher finds it difficult to quantify data (Brink, van der Walt, \& van Rensburg, 2010). In addition, it provides an indepth understanding of lived human experiences in the context in which they occur (Brink et al., 2010).

\subsection{Context of the study}

The study was conducted at the Mwolokohlo clinic in the Ndwedwe area.

Ndwedwe is a municipal area located in the iLembe district of KZN, South Africa. Ndwedwe has a population of approximately 140820 people living within this subdistrict and the surrounding areas (Census, 2011). The area is substantially underdeveloped, disadvantaged and poor (DOH, 2001). The Mwolokohlo clinic is a primary health care facility which falls under the Ndwedwe Community Health Centre (CHC).

Approximately 300 patients utilise the Mwolokohlo clinic's mental health services. The population for this study was the family members of mentally ill persons, who accompanied their relatives when they attended the mental health clinic for treatment. The family members of the persons with mental illnesses were those that were biologically related to the mentally ill patient or those who the patient regarded as family.

The non-probability purposive sampling method was used during this study. Botma, Greef, Mulaudzi, and Wright (2010) states that during purposive sampling, a particular individual is chosen because he or she shows a feature that is of relevance to the study. Data was collected from a sample of six different family members who met the eligibility criteria of the study. Data collection took place until saturation was reached. This allowed the researcher to obtain in-depth responses to the questions that were being asked.

\subsection{Inclusion criteria}

- Any family member living with a person diagnosed with any form of mental illness for at least one year or more.

- The family member is a biological sibling, father, mother or spouse of the person with a diagnosis of mental illness spanning at least one year or more or is considered by the patient to be a family member.

\subsection{Exclusion criteria}

- Mentally ill persons.

- A family member who is not a biological sibling, father, mother or spouse of the person diagnosed with mental illness and is not considered by the patient to be their family.

- A family member who is not living with the person diagnosed with mental illness.

- Minors - individuals below the age of 18 years.

\subsection{Data collection method}

The data was collected through interviews, using a selfdeveloped, semi-structured interview guide written in both English and Isizulu. The interview schedule was divided into two sections and was written in English and IsiZulu. Section A contained the demographic details of the participants. Section $\mathrm{B}$ contained the guiding interview questions. Both English and Isizulu were used as languages to collect information from participants because two out the six participants were not 
comfortable with using English as the only medium of communication. The interviews were recorded and transcribed verbatim, a translator was used to translate the data collected in Isizulu to English. The interviews took 30-45 min each.

\subsection{Data analysis}

Data was analysed inductively, based on Creswell's (2009) steps which involved: (1) transcribing interviews in audio form; (2) typing up field notes, reading the notes carefully and comparing them with the audio material to ensure the accuracy of the data; (3) re-reading transcriptions carefully to gain insight about the data and documenting ideas concerning it; (4) reading notes for the third time in order to identify the underlying meaning; (5) selecting the most interesting and informative parts of the interview, making side notes; (6) repeating this process to ensure that valuable information was not missed; (7) grouping similar topics together and finally (8) the formation of themes and sub-themes.

\section{Ethical considerations}

Ethical approval to conduct the study was obtained from the University of KwaZulu-Natal's research ethics committee. The provincial and district Department of Health was consulted to gain permission to conduct the study. The institution at which the data collection took place was also notified to seek written approval to conduct the study.

\subsection{Informed consent}

Participants were each provided with a verbal explanation and an information sheet regarding the nature of the research. Verbal and written consent was obtained. The written consent form and information sheet for the participants was presented in English and IsiZulu.

\subsection{Confidentiality}

This refers to the researcher's obligation of ensuring that all information regarding participants is not divulged to people who are not related to the study (Brink et al., 2010). The researcher did not make mention of participants' names in the written report. All written information obtained during the interview process was safely stored by the researcher and recorded information was put into a password protected folder which was only accessible to the researcher.

\subsection{Privacy}

To ensure privacy of the participants, the researcher conducted the interviews in a vacant consulting room in the clinic and closed doors during each of the interviews.

\subsection{Debriefing}

After the interviews had been conducted, the researcher held short, private debriefing sessions with each participant.
During this session, the researcher encouraged participants to verbalise any emotions they might have been experiencing. As a trained mental health nurse, the researcher then provided the relevant counselling to the participants. The researcher then referred all six participants to the social worker for short, individual counselling sessions in order to assure them of their psychological well-being.

\section{Trustworthiness}

Polit and Beck (2012) stated that it is important for qualitative studies and findings to provide evidence of reliability and validity, since qualitative research usually has elements of subjectivity. Brink et al. (2010) maintained that qualitative reliability and validity are not the same as quantitative reliability, and therefore trustworthiness is applied in qualitative research to denote the relevance and accuracy of the research study. Lincoln and Guba (1985) proposed four criteria for ensuring the trustworthiness of qualitative research.

\subsection{Credibility}

According to Polit and Beck (2012), this refers to the assurance of truthfulness regarding the collected and interpreted data. To ensure the credibility of this research project, the researcher collected the data using an audiotape and then transcribed the data. Data was collected until saturation and data analysis was done under the close supervision of the researcher's supervisor.

\subsection{Dependability}

Dependability refers to the ability of the data to stand the test of time and varying situations (Polit \& Beck, 2012). To ensure dependability, the researcher transcribed the audio data and thereafter read the data to ensure that it matched that which was in audio form. Once again, the researcher worked closely with the supervisor to ensure the correct transcription and validation of the analysed data and that the procedure followed was correct.

\subsection{Confirmability}

Confirmability, according to Klopper (2008), is the extent to which the researcher demonstrates objectivity in the interpretation of the research findings. This was ensured through submission of the collected data to the supervisor, who assisted in identifying themes and subthemes in the data. These were then compared with those of the researcher to determine and establish some form of congruence.

\subsection{Transferability}

Lincoln and Guba (1985) described transferability as the ability of the findings to be generalised to other settings or individuals. In order to ensure this, the researcher used purposive sampling during data collection. According to Bitsch (2005), purposively selecting participants facilitates transferability. In addition, the researcher provided a detailed 
description of the methods employed in executing the research, for the purpose of providing a clear understanding that will allow for easy replication of the study in another context.

\section{Presentation of results and discussion}

\subsection{Demographics description}

A total of six family members participated in the research study, four of them were females whilst only two were males. All of the participants were of a black race and were between the ages of 20 and 45 . Three participants had secondary school as their highest level of education whilst two were in possession of a college diploma and only one participant had a university degree. All of the participants had been living with the person with mental illness for more than four years and had a biological relationship with the patient.

\section{Results}

A total of six different family members of different patients, participated in the study. The profile of the participants was as follows (see Table 1):

The researcher identified key concepts and common ideas from which themes and sub-themes were developed. These themes were based on the research objectives.

\subsection{Stigma related experiences of family members}

\section{(a) Isolation}

The participants reported that they experienced stigma, as the community would keep them away from events happening in the community, with the fear that they would bring their mentally ill family members to the events, and that these family members would cause a disturbance. Participants also reported that they were often barred from entering the homes of people in the community, especially those of their neighbours, because they were fearful that their mentally ill relative would accompany them and likely cause disruptions in their homes.

This was supported by the following statements:
"The community has the attitude of distancing us from them and all the happenings of the area. They often want us to be alone, away from everyone .........."

(Aunt, age 38)

"It's hard for me because people like my neighbours end up not allowing me into their homes, as a result of fear."

(Brother, age 21)

“........ neighbours don't invite us into their homes or for their parties."

(Sister, age 30)

(b) Blame and exploitation

The participants revealed that they were often held responsible for wrong acts committed by their family member and were expected to pay for such acts. The participants revealed that in certain instances, their family member would be wrongly accused of committing an act of violence, so as to demand payment from the family for such wrong doing. Participants further revealed that the community blamed them for their family member's behaviour, citing a lack of proper punishment from the family as a reason for the bad behaviour. The participants also revealed that the community blamed them for the occurrence of mental illness in their family member, stating that it was attributed to their neglect of traditional practices. This was supported by the following statements:

"........ the community will often come home and say that our brother has stolen something or has broken something of theirs and now we must pay, because this person belongs to us and we are working. Sometimes the people in the community will say whatever they want to say and expect us to pay, so as a result, my father was always paying people because the community was claiming that he was breaking this and stealing this and that."

(Sister, age 30)

"They used to say that it is our fault that he does all the wrong things that he was doing because we were allowing him to do them ...........

Sometimes they used to even say that it's because we were not doing certain traditional things and we should therefore do this and that, and that used to be very hurtful, especially because

\begin{tabular}{|c|c|c|c|c|c|c|c|c|c|}
\hline Participant & Gender & $\begin{array}{l}\text { Age of } \\
\text { participant } \\
\text { (family } \\
\text { member) }\end{array}$ & Race & $\begin{array}{c}\text { Level of } \\
\text { education }\end{array}$ & $\begin{array}{c}\text { Relationship to } \\
\text { patient }\end{array}$ & Patient diagnosis & $\begin{array}{c}\text { Length of } \\
\text { stay with } \\
\text { patient }\end{array}$ & $\begin{array}{l}\text { Age of } \\
\text { patient }\end{array}$ & $\begin{array}{l}\text { Years of } \\
\text { illness }\end{array}$ \\
\hline Participant 1 & Male & 21 & Black & Secondary school & Brother & Psychosis & 20 years & 43 & 43 \\
\hline Participant 2 & Female & 36 & Black & Secondary school & Sister & Schizophrenia & 20 years & 55 & 20 \\
\hline Participant 3 & Female & 38 & Black & College diploma & Aunt & Schizophrenia & 29 years & 55 & 7 \\
\hline Participant 4 & Female & 30 & Black & College diploma & Sister & Bipolar disorder & 30 years & 35 & 35 \\
\hline Participant 5 & Female & 41 & Black & Secondary school & Mother & Down syndrome & 5 years & 14 & 14 \\
\hline Participant 6 & Male & 24 & Black & University degree & Aunt & Psychosis & 16 years & 47 & 22 \\
\hline
\end{tabular}


those things which they wanted us to do were against our belief system."

(Aunt age 38)

\section{(c) Community neglect}

One participant reported an incident in which their mentally ill family member became psychotic and set their home on fire, with resultant damage and loss of all their belongings. The participant reported that they sought help with this predicament, however obtained none from the community they were living in. Instead, it appeared that the community blamed them for the occurrence of this ordeal. This was supported by the following statements:

"One day he bunked hospital and came home and burnt the house because he wanted money and he couldn't get money ...... they did not help in any way. The help we got was from members of our church only."

(Sister, age 30)

"Our neighbours were sympathetic with us because our home got burnt down, but the rest of the community did not care."

(Aunt, age 38)

(d) Labelling and stereotyping

Participants also revealed that the community members would make nasty comments to them, as a result of being associated with a mentally ill person. The participants also stated that they would often be mocked, ridiculed and be treated strangely as a result of being associated with a mentally ill person. This was supported by the following statements:

"I come. I hear them gossiping and saying here is this person who has a mental family member, let's keep away from him. They even call my relative some names.

I don't hear them because they gossip."

(Sister, age 36)

"In the case of the community however, we became the joke. They would often mock us by repeating the silly things she would say."

(Aunt, age 38)

\subsection{Coping with stigma}

\section{(a) Emotion focused coping}

From the interviews conducted on all six participants, it was clear that all were stigmatised in some way or the other. Participants revealed that they employed a combination of ways to cope with being stigmatised as a result of being associated with a family member with mental illness. It was revealed that acceptance of their family played a significant role in helping them to cope, and in addition, praying about the situation provided some sort of relief when it appeared that the stigma became too much. Participants also revealed that they would often talk about how they were feeling when they were stigmatised. Also, talking about their family member in order to help people understand the situation they were in helped enable them to cope with the situation. This was supported by the following statements:

"Talking about her to people helped a lot because I really loved her. When people would come with that attitude that she is not normal and all that, I would just laugh it off and tell them of the things that she would do with us and her fun nature. I was very mature about it."

(Sister, age 30)

"I personally coped on my own, as there was no one to share my feelings with. I used to pray when I felt like things were too much to handle."

(Aunt, age 38)

(b) Problem focused coping

A participant stated that family members should seek professional help promptly when faced with a disturbing patient, so as to ensure that his or her disturbance did not affect the community, as this often lead to stigmatisation of the individual and the associated family. Participants also stated that families should keep their affected relative away from the public especially during periods of psychosis.

"They should take action immediately regarding their family member, especially if they see that he or she is starting to be troublesome. They should inform the relevant organisations and social workers so that such a person can be helped immediately, so that the community does not end up stigmatising the person and the family."

(Mother, age 41)

“...... I have sat down with him and talked to him to try and calm down when he is feeling like he is losing it. As a family sometimes we lock him away from the public during such time."

(Brother, age 21)

\subsection{Curb the stigmatisation of family members}

(a) Educating communities

When asked of the ways in which anti-stigmatisation of families could be promoted, participants recommended that communities be educated about the facts pertaining to mental illness. They asserted that such education would be helpful in curbing the stigma of the families of persons with mental illness, as factual information would enable the community members to be more understanding of the situation. Furthermore, respondents stated that education should also include the fact that mental illness was not contagious; that is, that families who had persons who were mentally ill were not 
necessarily mentally ill themselves. Participants revealed that this should be communicated clearly to communities, so that the communities would stop treating them negatively. This was supported by the following statements:

\begin{abstract}
"Maybe people can be brought in to the community to inform people not to discriminate against the people who are mentally ill and their families. They should know that the person who is sick in the family does not spread his sickness to all. It's important for them to know that the entire family is not mentally disturbed and therefore should not be treated as such."
\end{abstract}

(Sister, age 30)

"I would want them to be educated about the fact that if there is a person in the community who has mental illness, it does not mean that the entire family of that person has mental illness ........... ........"

(Sister, age 36)

\section{(b) Provision of various forms of support for family members}

Participants also revealed that the government and nongovernment organisations could play a role in curbing this stigma, by spearheading education campaigns and initiatives to promote anti-stigmatisation of the families. The government should also focus on families, assisting them by providing services to enable them to cope with the stigma that they face as a result of being associated with a mentally ill family member. Respondents suggested support groups as a viable means by which families could be helped to cope with the stigma that they faced. This was supported by the following statements:

“........ more outreach programmes to educate people about it. There should be some sort of forum or ways for them to engage. Go door to door and conduct surveys, where forms will be filled regarding families that actually have people who have mental illnesses. These families should be visited to assess how they are living and determine what their needs are, and what their fears are."

(Sister, age 30)

"..... go out into the community and tell them about the nature of a person who is mentally ill ... let them know that such a person is sick and unaware of what he is doing ."

(Mother, age 41)

\section{Discussion}

This study set out to explore the stigma related experiences of family members of persons with mental illness. The results of this study revealed that family related stigma of mental illness does exist. The patterns of stigma experiences reported by participants were found to be similar to those cited by other studies done both abroad and locally. Anagnostopoulos and Hantzi (2011) identified four patterns of stigma namely labelling, stereotyping, separating and emotion responses. Expounding of these four patterns, Link and Phelan (2001) stated that the result of such stigma may be self-stigma which may manifest in the form of poor self-image as a result of self-discrimination and isolation.

The existence of patterns of stigma; particularly family related stigma is profound, as it highlights an existence of negative stereotypical beliefs, behaviours and attitudes. The study by Rusch, Angermeyer, and Corrigan (2005) highlighted that negative stereotypical beliefs about mental illness were some of the causes of stigmatising attitudes amongst community members and even mental health professionals.

Research has revealed that the stigma of mental illness has to be studied within its socio-cultural context in order to understand its origins, meanings and consequences. When looking at the patterns of stigma in the socio-cultural context of this study, it is clear that the stigma patterns experienced by families of persons with mental illness is influenced by the traditional history regarding the origins of the occurrence of mental illness. The review of existing literature has demonstrated that historically people with mental illness have been stigmatized because they were thought to be possessed by some evil spirit or 'lunar force' and therefore had to be handled in a way that is different from the so called 'normal' (Uys \& Middleton, 2010). This pattern of stigma is documented throughout the history and origin of mental illness and can be said to be similar, both in the international and local sociocultural context.

Since stigma family related stigma arises by virtue of association with the person with mental illness (Dalky, 2012; Sanden et al., 2014), historical patterns of stigma of mental illness may be the reason for the stigma experienced by the family members of persons with mental illness.

Participants in this study revealed stigma experiences of isolation, blame, labelling, stereotyping and community neglect. These experiences are described below and supported by the relevant literature.

\section{(a) Isolation}

The results of this study revealed that the family members of persons with mental illness experience stigma by being isolated by community members. Isolation took place in the form of being prevented from attending social gatherings and as a result, these family members were prevented from making a contribution to the community. This experience is similar to that cited Sanden et al., (2014), who reported that the stigma of mental illness does get transferred from the individual with the mental illness to his or her family, resulting in the erection of social barriers. These barriers then jeopardise the social relationships among families, neighbours and the community in general.

Similarly, Gonzalez-Torres, Oraa, Aristeguie, FernandezRivas, and Guimon (2007) reported that isolation is a common manifestations of the stigma experienced by individuals and the families of people with mental illness. They reported that such stigma patterns lead to unfavourable reactions from patients and families and eventually lead to poor health outcomes. 


\section{(b) Blame and exploitation}

Participants of this study also revealed that they were often blamed by their community for the behaviour exhibited by their family member with mental illness. Often family members would endure being exploited by community members, who would demand payment for apparent damages caused by their mentally ill relatives. Participants reported that at times, these were false allegations. Research has revealed that family stigma often contains stereotypes of blame and shame. Blame is attributed to poor parenting skills, which supposedly results in mental illness in a child. On the contrary, Larson and Corrigan (2008) add that biological and medical models of mental illness reject the notion that poor parenting causes mental illness, however the general public still attributes poor parenting as the cause of mental illness and blames the family.

Karnieli-Miller et al. (2013) also found that the family members were blamed for the occurrence of the mental illness their relatives.

\section{(c) Community neglect}

The participants also revealed that the community was sometimes not interested in helping them in times of need, especially when they experienced problems relating to their mentally ill family member. The results of the qualitative study by Karnieli-Miller et al. (2013) also revealed community rejection and neglect in similar situations.

\section{(d) Labelling and stereotyping}

The findings of this study also revealed that family members were given nasty names by the community, as a result of them being associated with a mentally ill person. Participants reported being ridiculed and mocked by members of their community. According to Link and Phelan's (2001) Model of Stigma, stigma typically involves labelling and isolation, which leads to exclusion and a resulting status loss and discrimination. According to Byrne (2000) labels and stereotypes are selected perceptions that place people in categories exaggerating differences in groups in order to obscure these differences. Link, Yang, Phelan, and Collins (2014) mentioned that this is when a different trait which is deemed unusual by one particular dominant group is looked down upon, such that classes are or groups are formed that distinguish these individuals as inferior. Labels of "us" and "them" are created which results in the erection of psycho-social barriers.

\section{Coping with stigma}

The study revealed that participants employed diverse means of coping with the stigma they faced as a result of being associated with a family member with mental illness. Some of these coping mechanisms involved educating others about mental illness, verbalising their feelings and experiences with stigma, accepting and loving their family member regardless of the situation they were in and exercising their spirituality.
These findings are in line with those revealed by van der Sanden et al. (2014), who found that certain family members of people with mental illness used emotion focused coping to deal with the stigma they faced, such as denial, selfdistraction, acceptance, venting and behavioural disengagement; while other family members used problem focused coping mechanisms to deal with their stigma.

In their study of family members' experiences and efforts to cope with stigma, Karnieli-Miller et al. (2013) revealed that certain family members reported sharing their experiences with others as a means to cope with the stigma, while others adopted a strategy of secrecy. According to Heller, Roccoforte, Hsieh, Cook, and Pickett (1997), the decision to conceal is related to the fact that practicing advocacy by confronting stigma extorts an emotional toll, while the decision to reveal their experiences presents an opportunity to educate others about mental illness.

Similarly, Dalky (2012) cited that family members frequently employed concealment of the illness, seeking spiritual support or silence as a means of coping with the stigma they faced in similar circumstances.

\section{Curbing the stigma of families}

The results of this study revealed that the stigma faced by the family members of mentally ill persons can be curbed by the education of their communities regarding the facts surrounding mental illness. In addition, government can play a role in initiating drives and campaigns focussing of eliminating the stigma faced by the family members of persons with mental illness. South African legislation should also focus on protecting the family from stigma, instead of protecting the mentally ill person alone.

According to Larson and Corrigan (2008), mental health practitioners can play an active role in curbing stigma by developing care plans that cater for the stigma faced by both the person with mental illness as well as the family of the person with the mental illness. It is also suggested that the three approaches to erasing stigma, namely protest, education and contact, be applied to the stigma faced by families as well. Larson and Corrigan (2008) explain that the protest action is typically a moral plea for people to stop stigmatising them and this involves telling people to stop thinking negatively about the persons and their families affected by mental illness.

Education involves addressing myths about mental illness and this may typically include the myths about the family or family members associated with the person with mental illness. Education in the curbing of family stigma can also include the incorporation of family stigma and stigma interventions into the curriculum of mental health training programs.

Contact involves promoting or encouraging the social cohesion of mentally ill individuals and their families with the general public. Larson and Corrigan (2008) reveal that research has shown that single sessions of contact can change prejudice and discrimination.

Similarly, Sartorius and Schulze (2005) mentioned that education should also incorporate the use of media and other technology such as web interfaces in order to reach a wider 
audience; they also mention that such education should also be included in mental health curriculums.

On the other hand, literature by Byrne (2000) states that individuals affected by mental illness can in turn be turned into advocates; that is they should not assume the role of victim but rather should be actively involved in the interventions aimed at reducing the stigma of mental illness. It is stated that the individuals affected by stigma can be trained on how to educate others about the illness as well as determine what misconceptions exists so that they can be clarified. This together with a combination of other strategies can potentially curb stigma and remove the victim label that such individuals may assume when they experience stigma.

\section{Limitations}

The findings of the study are limited in that purposive sampling was done and the study was conducted in one rural community; therefore, the findings cannot be generalised to all rural communities. Although not generalisable, the study findings may help to provide baseline information on the ways in which family members (particularly within the South African rural context) experience stigma as a result of being associated with a family member with mental illness.

\section{Recommendations}

Based on the findings of this study, the researcher developed overarching recommendations aimed at providing a holistic approach to dealing with, and ultimately helping family members to cope with the stigma they face as a result of being associated with a person with mental illness. It is suggested that further research be done in the area of family related stigma, as this study was limited to just one setting (see Fig. 1).

\section{Overarching recommendations}

The recommendations below are directed towards providing a holistic approach to dealing with the stigma faced by the families and individual family members of persons with mental illnesses:

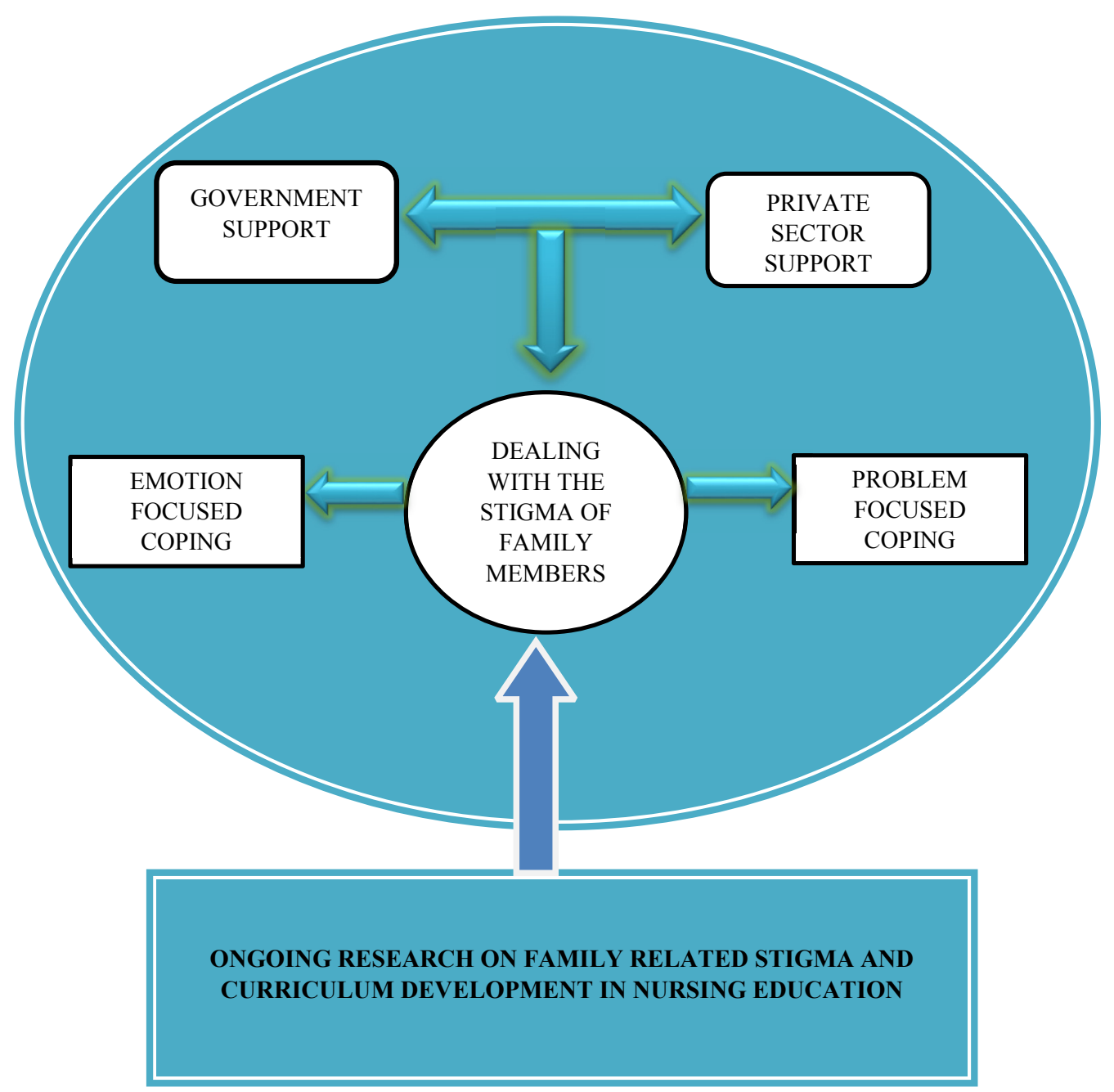

Fig. 1 - A recommended holistic approach to dealing with family related stigma of mental illness. 
1. Integration of government and private sector support; development of community based support groups to assist families to cope with stigma;

2. Employing a combination of emotion-focused and problem-focused coping skills;

3. Conducting ongoing research on family-related stigma;

4. Developing nursing curriculums to enable future community and mental health nurses to be able to diagnose the issue of family related stigma, thus equipping them with skills to be able to successfully plan and implement appropriate nursing interventions to deal with this problem.

\section{Conclusion}

The findings of this study revealed that family members of persons with mental illness are stigmatised in ways similar to those reported in previous studies conducted outside of the South African rural context. The participants used emotionfocused coping strategies in order to deal with this stigma. It was suggested that education of communities is a key factor to curbing this stigma. It is of paramount importance that family members of persons with mental illness be assisted to cope with stigma, especially since they play a crucial role in caring for their relatives. Therefore, there is a need for support groups to be developed at community level. Ground level education and support to the family from all sectors of the community is also necessary.

\section{Acknowledgements}

The researcher would like to convey his gratitude and acknowledgement to the family members who participated in the study, to the research supervisor, as well as to the institution where data collection took place for the support and encouragement throughout the duration of the study.

\section{R E F E R E N C E S}

Anagnostopoulos, F., \& Hantzi, A. (2011). Familiarity with and social distance from people with and social distance from people with mental illness: Testing the mediating effects of prejudiced attitudes. Journal of Community and Applied Social Psychology, 21(5), 451-460.

Bitsch, V. (2005). Qualitative research: A grounded theory example and evaluation criteria. Journal of Agribusiness, 23(2), 75-91.

Bonfine, N. (2015). Stigma, self-concept and stigma resistance among individuals with mental illness. Dissertation Abstracts International, 75(8).

Botma, Y., Greef, M., Mulaudzi, F. M., \& Wright, S. C. D. (2010). Research in health sciences (1st ed.). Cape Town: Heinemann Publishers.

Brink, H., van der Walt, C., \& van Rensburg, G. (2010). Fundamentals of research methodology for health care professionals (3rd ed.). Cape Town: Juta and company.

Byrne, P. (2000). Stigma of mental illness and ways of diminishing it. Advances in Psychiatric Treatment, 6(1), 65-72.
Caplan, G. (1993). Organisation of preventive psychiatry programs. Community Mental Health Journal, 29(4), 367-395.

Census South Africa. (2011). [Online]. Available at: http://www. statssa.gov.za (Accessed 18 July 2015).

Creswell, J. W. (2009). Research design: Qualitative, quantitative and mixed methods approaches. Los Angeles: Sage Publications.

Dalky, H. F. (2012). Perceptions and coping with stigma of mental illness: Arab families' perspective. Issues in Mental Health Nursing, 33, 486-491.

Department of Health. (2001). [Online]. Ndwedwe community health Centre. Available at: http://www.kznhealth.gov.za/ ndwedwechc.htm (Accessed 18 July 2015).

Gonzalez-Torres, M. A., Oraa, R., Aristeguie, M., FernandezRivas, A., \& Guimon, J. (2007). Stigma and discrimination towards people with schizophrenia and their family members. Social Psychiatry Epidemiology, 42, 14-23.

Hayward, P., \& Bright, J. A. (1997). Stigma and mental illness: A review and critique. Journal of Mental Health, 6(4), 345-354.

Heller, T., Roccoforte, J. A., Hsieh, K., Cook, J. A., \& Pickett, S. A. (1997). Benefits of support groups for families of adults with severe mental illness. American Journal of Orthopsychiatry, 67(2), 187198.

International Council of Nurses. (2015). Human rights of the mentally ill in Indonesia. International Nursing Review, 62(2), 153-161.

Karnieli-Miller, O., Perlick, D. A., Nelson, A., Mattias, K., Corrigan, P., \& Roe, D. (2013). Family members of persons living with a serious mental illness: Experiences and efforts to cope with stigma. Journal of Mental Health, 22(3), 254-262.

Klopper, H. (2008). The qualitative research proposal. Curationis, $31(4), 62-72$.

Larson, J. E., \& Corrigan, P. (2008). The stigma of families with mental illness. Academic Psychiatry, 32(2), 87-91.

Lincoln, V. S., \& Guba, E. G. (1985). Naturalistic enquiry. California: Sage Publications.

Link, B. G., \& Phelan, J. C. (2001). Conceptualising stigma. Annual Review of Sociology, 27, 363-385.

Link, B. G., Yang, L. H., Phelan, J. C., \& Collins, P. Y. (2014). Schizophrenia Bulletin, 30(3), 511-544.

Polit, D., \& Beck, C. T. (2012). Essentials of nursing research. Appraising evidence for nursing practice. Lippincott: Williams \& Wilkins.

Rithsher, J. B., Otilingam, P. G., \& Grajales, M. (2003). Internalised stigma of mental illness: Psychometric properties of a new measure. Psychiatry Research, [e-journal], 121, 31-49. Available at: http://www.sciencedirect.com (Accessed 20 March 2015).

Ritsher, J. B., \& Phelan, J. C. (2004). Internalised stigma predicts erosion of morale among psychiatric outpatients. Psychiatry Research, [ejournal], 129, 257-265. Available at: http://www. sciencedirect.com (Accessed 20 March 2015).

Rusch, N., Angermeyer, M. C., \& Corrigan, P. W. (2005). Mental illness stigma: Concepts, consequences, and initiatives to reduce stigma. European Psychiatry, [e-journal], 20, 529-539. Available at: http://www.sciencedirect.com (Accessed 20 March 2015).

Sanden, R. M., Bos, E. R., Stutterheim, S. E., Pryor, J. B., \& Kok, G. (2014). Coping with stigma by association and family burden among family members of people with mental illness. The Journal of Nervous and Mental Diseases, 202(10), 710-715.

Sartorius, N., \& Schulze, H. (2005). Reducing the stigma of mental illness: A report from a global programme of the World Psychiatric Association. Cambridge: Cambridge University Press.

Shives, L. B. (1994). Basic concepts of psychiatric mental health nursing (3rd ed.). Philadelphia: J.B. Lippincott Company.

Stuart, H. (2004). Stigma and work. Community Health and Epidemiology, 5(2), 100-111.

Ustun, T. B. (1999). The global burden of mental disorders. American Journal of Public Health, 89(9), 1315-1318. 
Uys, L., \& Middleton, L. (2010). Mental health nursing: A South African perspective (6th ed.) CapeTown: Juta and Company. Waite, M., \& Hawker, S. (2009). Compact Oxford dictionary \& thesaurus (3rd ed.). New York: Oxford University Press.

Wong, C., Davidson, L., Anglin, D., Link, B., Gerson, R., Malaspina, D., et al. (2009). Stigma in families of individuals in early stages of psychotic illness: Family stigma and early psychosis. Early Intervention in Psychiatry, 3, 108-115. World Health Organisation. (2004). A glossary of terms for community health care and services for older people. Geneva: WHO Press. 